Food intake

\section{The social facilitation of food intake}

\section{R F Drewett}

\section{Perspective on the paper by Lumeng and Hillman (see page 384)}

$\mathrm{S}$ chools making valiant efforts to introduce the Jamie Oliver diet will have some sympathy with Oberlin College in Ohio, USA, which sought in the early 19th century to introduce the equally healthy (and more morally improving) Sylvester Graham diet, and found, I am sorry to say, that rebellious students took to leaving the campus to eat more palatable foods elsewhere. Even a professor refused to stop bringing in pepper to liven up his college meal, and for setting so bad an example the college was eventually obliged to sack him. I learned these interesting facts checking out the graham cracker, used by Julie Lumeng and Katherine Hillman in their study. The graham cracker, which is more like a digestive biscuit than what would commonly be called a cracker in the UK, is the sole surviving remnant of the Graham diet.'

Eating is one of our most obviously social activities. Immediately after birth, it invariably involves an adult as well as the infant, most usually the child's mother. From weaning onwards other children and other adults can also be present at meals, and in older children and adults the social context of eating varies very widely, from eating alone in solitude to eating communally in large gatherings. Perhaps surprisingly, there is now very strong evidence in adults that the number of people present at a meal is not only an important determinant of energy intake but one of the most important. People regularly eat more when they eat in groups than when they eat alone (up to $50 \%$ more), and the larger the group the more they eat. Struggling as we are with an excess of energy intake over energy expenditure, the significance of this will be obvious.

Research in this area has been summarised in a characteristically fine review by Herman et al. ${ }^{2}$ Much of the published research on the social facilitation of eating in humans they mention is from John de Castro, and utilises analyses of 7 day food diaries, supplemented by ratings of hunger, mood and anxiety at the beginning and end of meals and by records of the number of people eaten with. ${ }^{3}$ These studies relate to normal food intake in the normal environment, and therefore have strong external validity. They do depend, however, on accurate recording by the participants, and as in all such studies, causal inference is difficult. Further analysis has shown, however, that the effect does not depend on a confounding with alcohol consumption or with eating in restaurants, or on the meals that are normally smaller, such as breakfast, normally also being less social. And the effect is also found when group size is manipulated experimentally in laboratory conditions.

This is a robust finding, then. But all these data come from adults, so it is of considerable interest that Julie Lumeng and Katherine Hillman now present some related findings from children 2-6 years old. ${ }^{4}$ In their study they compared children eating snacks in groups of three and groups of nine. Each session was video taped and intakes determined by counting the number of graham cracker portions consumed by each child. Latency to eat, eating rates and meal durations were also determined from the tapes. They describe their study as "observational", meaning, in this context, that they actually observed the children while they were eating. This unfortunately ambiguous term is also used by medical statisticians to mean that no variable in the study has been manipulated, but in this study group size was manipulated, so its internal validity is high. Children within each classroom were randomised into groups of three, and the groups of three then randomised into groups of nine. Data from each child were collected in both the smaller and the larger groups, and comparisons were made of their food intake and eating behaviour during the meals. The results showed that food intake was related both to meal duration and to group size, and that the two interacted. Group size did not affect food intake if the meals were short, but increased it if the meals were long. The authors suggest that increased arousal in the larger groups is likely to underlie the increased food intake.

There is, of course, the further question of external validity. What happens in real life, over days rather than over a single meal? This will depend partly on the extent to which the extra energy consumed in the larger groups reduces subsequent intake. Although energy compensation of this kind undoubtedly occurs, its precision probably varies with the kinds of food available and it certainly varies with the age and adiposity of the child. ${ }^{56}$ Measuring energy intake over extended periods in children is notoriously difficult to do precisely, and would not be easy to do on the scale that would be required for studies in this area. ${ }^{7}$

I do not suppose we would wish to encourage solitary eating, which is a risk factor for the later development of eating disorders, ${ }^{8}$ but there may be scope for schools to alter the seating arrangements in their diners by substituting smaller for larger tables, perhaps, which is not likely to do any harm even if it is hard to prove it does any good. Further research work on the interactions between children at meal times would surely also be desirable. It has been known for some time that such interaction affects food choice and food preferences, in ways that clearly can be modified. ${ }^{910}$ In showing that, as in adults, it may also directly affect energy intake Lumeng and Hillman have opened up a further area for investigation, and one that may turn out to be of considerable importance.

Arch Dis Child 2007;92:377.

doi: 10.1136/adc.2006.108332

Correspondence to: R F Drewett, Department of Psychology, University of Durham, Durham, UK r.f.drewett@durham.ac.uk

Competing interests: None.

\section{REFERENCES}

1 Graham cracker. In: Wikipedia, The Free Encyclopedia. Available from http:// en.wikipedia.org (accessed 27 February 2007).

2 Herman CP, Roth DA, Polivy J. Effects of the presence of others on food intake: a normative interpretation. Psychol Bull 2003:129:873-86.

3 de Castro JM. Social facilitation of duration and size but not rate of the spontaneous meal intake of humans. Physiol Behav 1990;47:1 129-35.

4 Lumeng JC, Hillman $\mathrm{KH}$. Eating in larger group increases food consumption. Arch Dis Child 2007;92:384-7.

5 Birch LL, Deysher M. Caloric compensation and sensory specific satiety: evidence for self regulation of food intake by young children. Appetite 1986;7:323-31

6 Johnson SL, Birch LL. Parents' and children's adiposity and eating style. Pediatrics 1994;94:653-61.

7 Birch LL, Johnson SL, Andresen G, et al. The variability of young children's energy intake. N Engl J Med 1991;324:232-5.

8 Martínez-González MA, Gual P, Lahortiga $F$, et al Parental factors, mass media influences, and the onset of eating disorder in a prospective population-based cohort. Pediatrics 2003;111:315-20.

9 Horne PJ, Lowe CF, Bowdery M, et al. The way to healthy eating for children. Br Food J 1998; 100:133-40.

10 Horne PJ, Lowe CF, Fleming PFJ, et al. An effective procedure for changing food preferences in 5-7year-old children. Proc Nutr Soc 1995;54:441-52. 